\title{
Complementary Methods in Breast Cancer Therapy
}

\author{
Volker Hanf \\ Frauenklinik, Klinikum Fürth, Germany
}

BREAST CARE is a forum for those dealing with all aspects of breast disease. The focus of this issue addresses mainly the practising clinician. It offers the opportunity to deal with a subject that many of us try to avoid in order to soundly remain on the solid ground of evidence-based medicine, where causal relationships are plausible and the answers dependable.

However, life in the clinic is different. We are dealing with real patients who are much less interested in discussing scientific circumstance and evidence with their health science administrator than in seeking firstly emotional support and secondly sound medical advice and guidance from their chosen doctor. One danger of modern clinical practice lies in too much administration of scientifically supported medical technology and too little empathic companionship. The first approach is focussed on scientific expertise and necessarily leaves the patient a passive layperson void of a chance to contribute herself to the aim of cure, the latter acknowledges the individual urge 'to do something oneself'.

This urge is clearly described in the contribution of U. Kappler [1], representing the patients' advocates group mammazone, Munich, Germany. Getting active is a natural reaction to an impending danger. Not patient(-ly) waiting for the aggressor to strike but to attack oneself, or, failing that, turning to run away.

It's all about getting active. Indeed, playing sports and thereby reducing bodyweight towards a normal body mass index (BMI) is a proven adjuvant therapy adding benefits in the overall scale of adjuvant chemotherapy [2]. An equally important intervention can be the reduction of BMI by adhering to a fat reduced and fat modified diet plan [3].

All the various aspects of possible adjuncts to our tried and trusted scientific western medicine are fields that are explored by patients to develop activity for themselves - and be this activity only the act of submission under the advice of a nonmedical practitioner. These aspects are widely called comple- mentary and alternative methods (CAM). These two parts have to be differentiated with care; complementary methods are added to an existing scientific treatment plan, holding the potential of e.g. drug interference, whereas alternative methods are employed instead of proven treatments. We do not want to deal with the latter. While complementary methods may be physical interventions, such as Tai-Chi or acupuncture, many complementary methods comprise drug applications.

Drug therapy, particularly, holds an ancient mystic promise of cure. The survey by J. Beuth [4] casts light on various forms of complementary drug treatments. Since in BREAST CARE we aim to inform the reader on scientifically sound therapies, we focus on these and try to demonstrate where the promise of added benefits lies. The article by U. Gröber [5] on micronutrients gives a good example of a complementary treatment that could factually fulfil its task to the word's truest meaning: namely complementing a modern medical treatment with the chance to synergise with respect to anti-tumour activity and protect from possible treatment side effects. A recent example of quackery is dissected by E. Ernst [6]. Carctol, widely publicised in the UK as a cancer cure offers benefits only to its vendors.

Isoflavones, oestrogeneic compounds found in soy products are ingredients of eastern diets. Since e.g. Japanese women have a reduced risk for breast cancer as compared to Western women, it has been hypothesized that early childhood exposure to oestrogeneic soy ingredients might be responsible for later cancer protection. Not surprisingly, cancer survivors aim to use this alleged anti breast cancer activity for themselves. However, as Stubert and Gerber [7] point out, this is a common misunderstanding: trying to deduct from the primary prevention setting to the adjuvant or the palliative situation. The complicated dose-response relationship of e.g. genistein, yielding partially oestrogeneic or anti-oestrogeneic effects makes the recognition of isoflavones as friend or foe difficult.

\section{KARGER}

Fax +497614520714

Information@Karger.de

www.karger.com (c) 2009 S. Karger GmbH, Freiburg

Accessible online at:

www.karger.com/brc 
Other important aspects that are well worth studying could not be included in this issue due to various reasons. Anyway, whichever selection we would have chosen, it would have been incomplete. So what does Breast CARE intend to explicate in this year's first issue? Complementary medicine must be practiced by the scientifically oriented clinician. The patient's advoate, U. Kappler, puts it quite clearly:

Patients want to have oncologists and gynaecologists, not just some general practinoners or non-medical practitioners, who can educate them about complementary (or alternative) medicine. They want doctors that take them and their desire to actively contribute to their cure seriously. They want doctors that know more than just guideline-oriented treatment and follow-up but are also knowledgeable about complementary medicine or can at least guide them to someone who is.

In other words: take the myth out of complementary medicine and put it to the test like other parts of our scientific medicine. Now we have the instruments to do it. Recently, a systematic Cochrane review was published on mistletoe therapy in oncology. Other Cochrane reviews on CAM methods are in preparation. The author of the review on mistletoe [8], M. Horneber, has agreed to explicate on the aspects of mistletoe therapy in breast cancer in BREAST CARE later on this year. The European Union has dedicated a website to CAM practices in cancer: www.cam-cancer.org. Here, the interested physician (and patient) finds links and summaries to scientific evidence pertaining to CAM. Lastly, the Breast Organ Commission of the German working group gynaecological oncology (AGO) yearly updates treatment recommendations, as in every aspect of breast cancer, also on CAM at www.ago-online.org/index.php?site=mamma_guide\&lang=de. So we have the tools and no excuses.

We, the doctors who claim for ourselves to practice medicine on an a scientific basis are the ones that should make themselves knowledgeable and advise our patients to the best of our knowledge. - And we should learn from the quacks: that it is important that we give our patients the feeling that we care and that we take them seriously.

\section{References}

1 Kappler U: Komplementäre Therapie aus der Sicht von Krebspatientinnen. Breast Care 2009; DOI: $10.1159 / 000203077$.

$\checkmark 2$ Holmes MD, Chen WY, Feskanich D, Kroenke $\mathrm{CH}$, Colditz GA: Physical activity and survival after breast cancer diagnosis. JAMA 2005;293:2479-86.

3 Gerber B, Hanf V: Studie belegt: Fettarme Ernährung reduziert das Rezidivrisiko. Frauenarzt 2007; 48:465.
4 Beuth J: Evidence-based complementary medicine in breast cancer therapy. Breast Care 2009;4: DOI: 10.1159/000194306.

5 Gröber U: Antioxidants and other micronutrients in complementary oncology. Breast Care 2009;4: DOI: $10.1159 / 000194972$.

6 Ernst E: Carctol: Profit before patients? Breast Care 2009;4: DOI: 10.1159/000193025.
7 Stubert J, Gerber B: Isoflavones - mechanism of action and impact on breast cancer risk. Breast Care 2009;4: DOI: 10.1159/000200980.

8 Horneber MA, Bueschel G, Huber R et al.: Mistletoe therapy in oncology. Cochrane Database Syst Rev 2008;2:CD003297. 